\title{
PENINGKATAN EFISIENSI KERJA SERTA MEMINIMALISIR WASTE PADA DIVISI KAROSERI MENGGUNAKAN METODE LEAN MANUFACTURING (STUDI KASUS PT. SUMBER URIP SEJATI)
}

\author{
Nurul Habibi Ahmad ${ }^{(1)}$, Pregiwati Pusporini ${ }^{(2)}$ \\ ${ }^{1}$ Mahasiswa Teknik Industri, Fakultas Teknik, Universitas Muhammadiya Gresik \\ ${ }^{2}$ Dosen Teknik Industri, Fakultas Teknik, Universitas Muhammadiyah Gresik Jl. Sumatera No. \\ 101 GKB-Gresik 61121. \\ e-mail : oldstar.biebie@gmail.com
}

\begin{abstract}
ABSTRAK
PT. Sumber Urip Sejati adalah perusahaan yang bergerak dalam bidang perakitan karoseri trailer 40 feet 45 feet dan 60 feet, Kondisi yang terjadi saat ini adalah sering terjadi permasalahan yang diakibatkan karena proses perakitan terlalu lama yang tidak sesuai dengan komitmen awal dengan konsumen. Tahapan-tahapan yang diterapkan dalam penelitian ini adalah (1) penggambaran VSM current state dan future state (2) mengetahui value added dan non value added didalam proses perakitan (3) membuat skala prioritas terhadap 7 waste untuk meminimalisir pemborosan di proses perakitan trailer 40 feet. Berdasarkan hasil penelitian, didapatkan pemborosan yang paling sering terjadi adalah waiting $(20,3 \%)$, motion $(20,2 \%)$, Innappropriate processing $(18,8 \%)$, dan inventory $(18,1 \%)$. Mapping tools yang digunakan berdasarkan hasil konversi matrik adalah proses activity mapping (39,3\%). Dari proses activity mapping dapat diketahui bahwa proporsi waktu inspection sebesar (6,76\%). Setelah perbaikan didapatkan hasil proporsi inspeksi sebesar $(4,94 \%)$. Untuk nilai value added ratio (VAR) sebelum perbaikan sebesar $88,52 \%$ setelah penerapan perbaikan nilai var menjadi $(92,29 \%)$. Dalam arti perusahaan yang dulunya merakit trailer 40 feet selama 22 hari berkurang menjadi 18 hari sehingga waktu proses pengerjaan nya lebih cepat dari due date konsumen.
\end{abstract}

Kata Kunci : Lean manufacturing, Value Stream Mapping (VSM), Value Stream Analysis Tools (VALSAT), Failure Measure effect analyze (FMEA)

1. Pendahuluan

\subsection{Latar Belakang}

Pada era globalisasi ini, tingkat persaingan antar perusahaan manufaktur semakin ketat. Dengan meningkatnya persaingan antar perusahaan, pelanggan semakin tidak bersedia untuk menunggu mendapatkan pesanannya. Oleh karena itu, perusahaan yang mampu menghasilkan produk yang tepat waktu dan tepat jumlah merupakan perusahaan yang mampu bertahan dalam persaingan.

Di dalam Industri rancang - bangun kendaraan, proses perencanaan hingga produksi massal dilakukan secara matang dan terukur. Kepresisian dengan tingkat efisiensi tinggi adalah hal yang mutlak saat ini, dengan tetap mempertahankan kualitas terbaiknya agar mampu bersaing secara global. Sehingga PT. Sumber Urip Sejati yang berdiri sejak tahun 1981 yang berpusat di Surabaya menawarkan kualifikasi tersebut, melalui lini produknya yang mencakup komponen suku cadang (autoparts) dan eksport import (sparepart) di industri kendaraan. Di dalam Divisi
Karoseri (auto parts) atau body builder Truck. PT.Sumber Urip Sejati menawarkan berbagai macam jenis untuk pemasangan lantai / dek trailer juga pembuatan dump truck, load bak, box, mixer, concrate pump. Dengan berbagai jenis ukuran sesuai kebutuhan konsumen.

PT. Sumber Urip Sejati merupakan perusahaan yang menganut "Make To Order" dan perlu untuk menyelesaikan tepat waktu pada proses assembling nya. Berdasarkan wawancara dengan pihak manajer divisi karoseri perusahaan belum mampu melaksanakan assembling nya tepat waktu sesuai dengan "due date" yang diberikan oleh konsumen. Karena pada proses karoseri terdapat permasalahan yang sering terjadi yaitu adanya pemborosan (waste) waktu tunggu (waiting), gerakan yang tidak berguna (unnecessary motion), persediaan yang tidak penting (unnecessary inventory) proses yang tidak tepat (inappropriate processing) dan menganggur (Iddle Time) yang dapat dilihat pada tabel 1.2. Dengan adanya Pemborosan (waste) 
Tabel 1.2 Identifikasi a aval waste pada proses perakitan trailer 40 feet

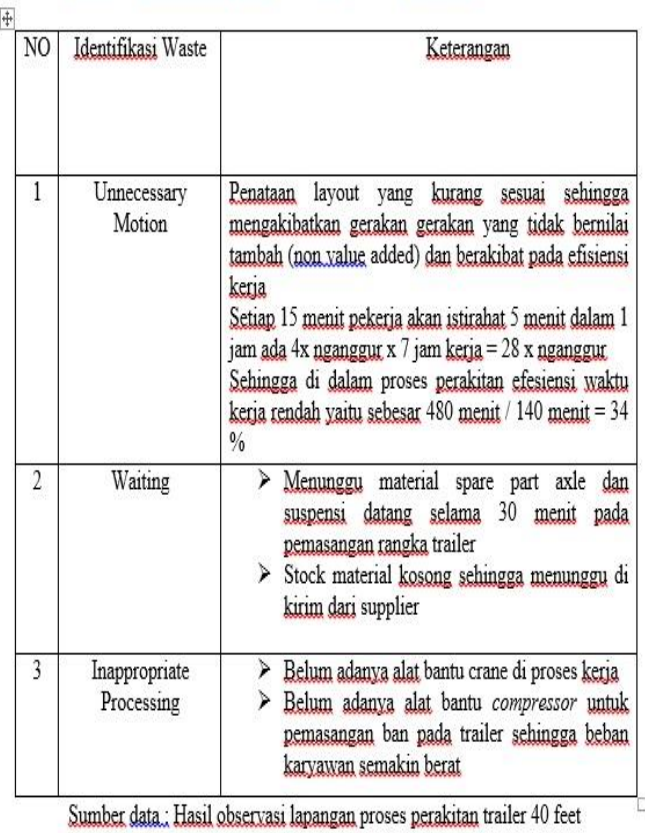

tersebut maka completion time proses assembling menjadi lebih lama. Untuk mendapatkan completion time yang lebih pendek maka perusahaan perlu mengurangi pemborosan (waste) yang ada. Dengan demikian completion time proses assembling pada divisi karoseri diharapkan menjadi lebih pendek dan produktifitas perusahaan meningkat.

Berdasarkan pengamatan pada divisi karoseri di PT. Sumber Urip Sejati memungkinkan adanya pemborosan (waste) terjadi dikarenakan disetiap variable dari identifikasi awal (Tabel 1.1) kurang adanya penanganan khusus dari pihak perusahaan. Dan perusahaan juga tidak memberikan alternatif pada proses perakitan (assembling). Maka dari itu diperlukan penanganan untuk menentukan penyebab terjadinya pemborosan yang terjadi didalamnya. Salah satu pendekatan yang dapat digunakan untuk mengurangi pemborosan adalah lean manufacturing, dan Value Stream Mapping (VALSAT).

Dengan menggunakan metode Lean Manufacturing ini diharapkan PT. Sumber Urip Sejati dapat mengurangi pemborosan yang terjadi sehingga dapat meningkatkan efisiensi kerja dan memenuhi due date yang diberikan oleh konsumen.

\subsection{Rumusan Masalah}

Berdasarkan penjelasan latar belakang masalah diatas, maka permasalahan dalam penelitian ini adalah :

1. Bagaimana pendekatan lean manufacturing sebagai upaya meminimalkan waste dan meningkatkan efisiensi kerja pada divisi karoseri ?

\subsection{Tujuan Penelitian}

Tujuan yang ingin dicapai dalam penelitian ini adalah

1. Mengidentifikasi waste yang terjadi pada proses perakitan (assembling).

2. Mengukur waste yang paling berpengaruh pada proses perakitan (assembling).

3. Mengidentifikasi faktor-faktor yang sering menjadi penyebab terjadinya waste pada perakitan (assembling).

4. Memberikan rekomendasi perbaikan beserta langkahlangkah yang perlu dilakukan untuk meminimalisir waste

\section{Tinjauan Pustaka}

\subsection{Lean Manufacturing}

Menurut James Womack dan

Daniel Jones dalam Kusuma (2010) untuk menjadi lean manufacturing dibutuhkan cara berfikir yang berfokus untuk menjadikan produk mengalir melalui tahapan yang memberikan nilai tanpa adanya hambatan (one piece flow), sebuah pull system yang bersumber dari permintaan customer untuk mencapai interval proses yang pendek dan membudayakan melakukan continuous improvement dengan tekun.

\subsection{Value Stream Mapping}

Value stream mapping adalah semua tindakan (value added dan non value added) saat ini diperlukan untuk menbawa produk melalui aliran utama untuk setiap produk: (1) aliran produksi dari aliran bahan baku sampai ke pelanggan dan (2) aliran design dari konsep sampai kepeluncuran (Rother \& Shook, 2003).

\subsection{Value Stream Analysis Tools (Valsat) \\ Hines \& Rich (1997) \\ mengembangkan tool yaitu VALSAT}


harapanya adalah untuk mempermudah pemahaman terhadap value stream yang ada dan mempermudah untuk membuat perbaikan yang berhubungan dengan pemborosan (waste) yang terdapat didalam value stream.

\subsection{Seven Mapping tools}

Tujuh detail mapping tools yang memiliki kemampuan dan manfaat masingmasing untuk menemukan pemborosan (waste). Setiap alat mempunyai bobot low, medium dan high sesuai dengan ketentuan peringkatnya, dan sekaligus menunjukkan skor yang dapat mengindikasi besar kecilnya pengaruh pemborosan (waste influence) pada mapping yang dipilih.

\subsection{Kegiatan-Kegiatan Value added Dan Non Value Added}

Proses transformasi bahan baku menjadi barang jadi adalah tujuan dari setiap perusahaan manufacturing (Davy, 2009). Proses yang membuat bahwa transformasi yang mungkin adalah hasil dari dua kegiatan yang berbeda, kegiatan yang memberi nilai tambah dan kegiatan yang tidak memberi nilai tambah.

2.6 FMEA (Failure Mode Effect Analysis)

FMEA merupakan suatu metode yang digunakan untuk mengidentifikasi dan memberikan prioritas kegagalan potensial yang terjadi pada sebuah proses atau produk (Kmenta, 2000).

\section{Metodologi Penelitian}

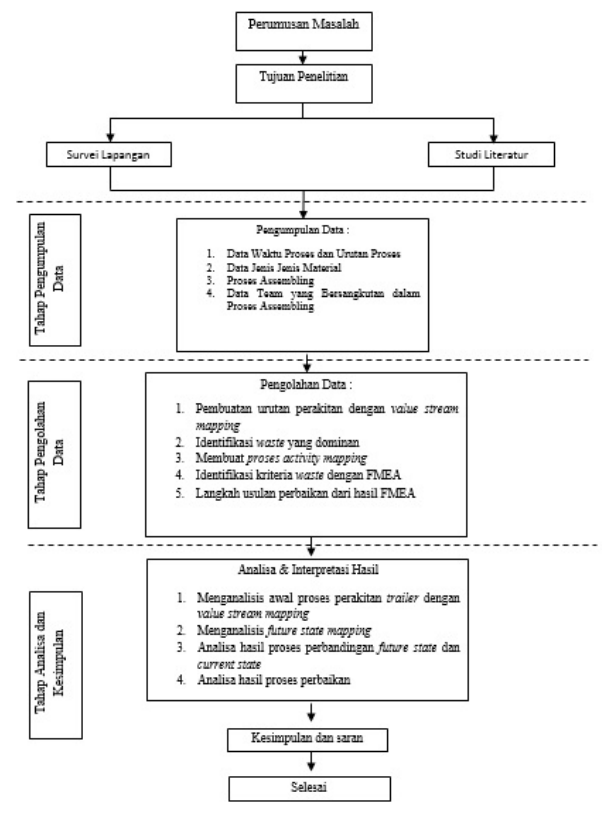

4. Hasil Penelitian Dan Pembahasan 4.1 Hasil Identifikasi pemborosan (waste)

Berdasarkan hasil identifikasi pemborosan menggunakan kuisioner, sesuai hasil yang didapatkan maka jenis pemborosan yang paling dominan adalah waiting, inventory, innapropriate processing, dan unnecessary motion

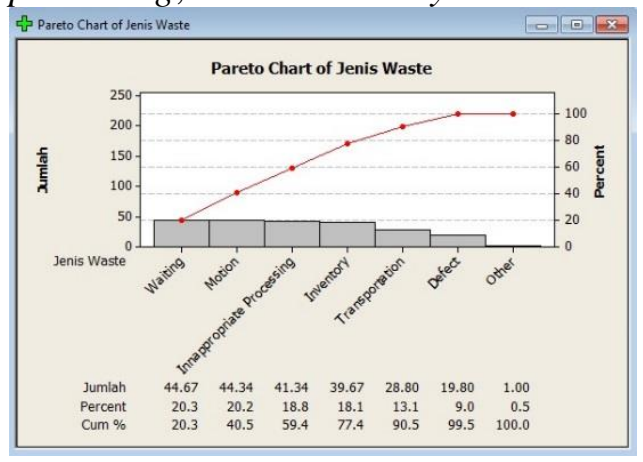

4.2 VALSAT

Dari hasil konversi VALSAT didapatkan Tools yang dominan untuk mengidentifikasi waste yang terjadi adalah Process Activity Mapping (39,3\%), Supply Chain Respone Matrix $(20,2 \%)$ dan Quality Filler Mapping $(13,1 \%)$, Demand Amplification mapping $(12,4 \%)$, Decision point analysis (8,2\%), Product variety funnel $(5,1 \%)$, Phisycal structure $(1,7 \%)$.

Keterangan tentang pemilihan Tool :

Process activity mapping (PAM) tool digunakan untuk memetakan setiap 
aktivitas didalam setiap proses perakitan

PAM sangat berguna untuk mengidentifikasi VA,NVA, \& NNVA. Sedangkan SCRM (Supply chain respone matrix) digunakan untuk mendeskripsikan tentang kondisi lead time untuk setiap proses dan jumlah persediaan. Di PT. Sumber Urip Sejati ini persediaan di atur oleh pihak divisi lain. Sehingga divisi karoseri hanya akan merakit design layout yang sudah dipesan oleh konsumen. Tool Quality Filler Mapping (QFM) digunakan untuk mengevaluasi waste defect kurang cocok digunakan, dikarenakan waste defect yang kecil dan kebanyakan dari defect tersebut berupa reject.

\subsection{Process Activity Mapping (PAM)}

Pembuatan tools ini memerlukan pengamatan secara langsung terhadap proses, aktivitas tiap proses, jarak, waktu serta tenaga kerja yang terlibat. Hasilnya di inputkan kedalam tabel dimana setiap aktivitas akan dikelompokkan kedalam lima jenis aktivitas, yaitu : operasi, transportasi, inspeksi, delay dan storage. Dari tabel ini didapatkan bahwa aktivitas value added merupakan sebuah operasi, maka akan didapatkan value added activity. Operasi adalah aktivitas yang bernilai tambah (VA). Sedangkan inspeksi transportasi dan storage adalah aktivitas yang idak bernilai tambah tapi diperlukan (NNVA). Delay adalah aktivitas yang tidak bernilai tambah (NVA).

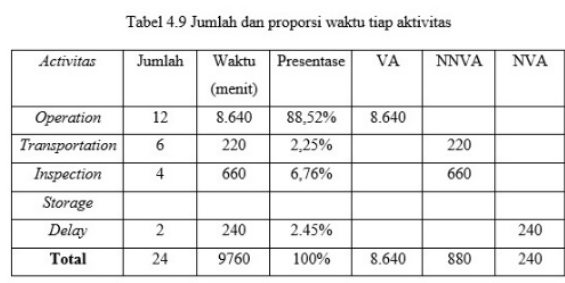

Dari tabel 4.9 dapat diketahui bahwa pada proses perakitan trailer 40 feet, proporsi waktu operation menghabiskan waktu yang paling banyak sebesar 8.640 menit atau setara 144 jam $(88,52 \%)$ dari konsumsi waktu secara keseluruhan. Selanjutnya proporsi waktu terbesar kedua adalah aktivitas inspection dengan proporsi $6,76 \%$ dan ternyata terdapat delay dengan proporsi $2,45 \%$.

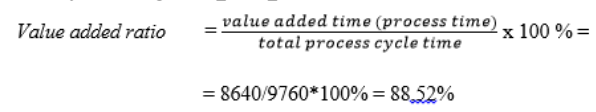

4.4 Identifikasi Faktor- Faktor Pemborosan dengan 5 whys

Pada bagian ini akan diidentifikasi penyebab terjadinya waste seperti, inventory, motion, waiting dan inappropriate processing sesuai hasil observasi, wawancara dan kuisioner terlihat pada tabel 4.10 Dengan mengidentifikasi seluruh waste dengan 5 whys

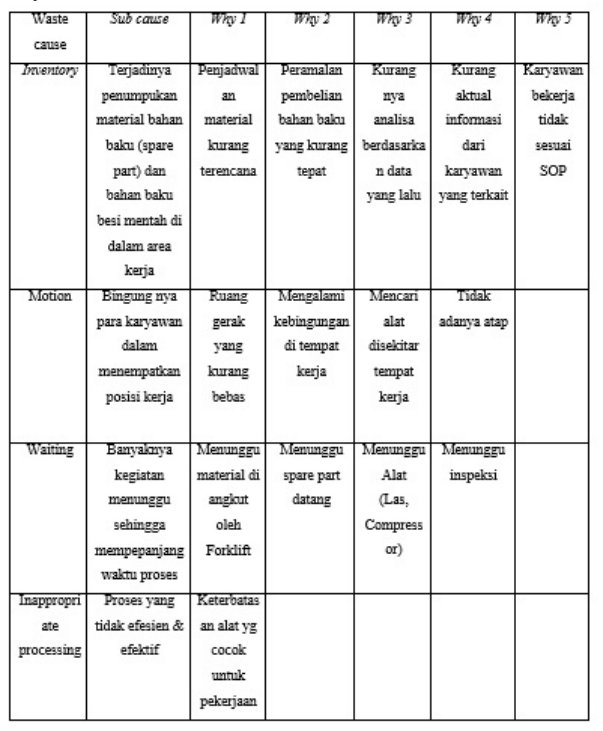

4.5 Identifikasi kriteria-kriteria waste dengan FMEA

FMEA merupakan suatu metode yang digunakan untuk mengidentifikasi dan memberikan prioritas kegagalan potensial yang terjadi pada sebuah proses atau produk (Kmenta, 2000). Dalam FMEA ada 3 faktor yang dinilai terkait dengan resiko yang secara standar ditetapkan sebagai faktor yang akan dikalikan untuk mendapatkan nilai Risk Priority Number (RPN), ketiga faktor tersebut adalah :

\section{Severity}

Uraian kriteria dari rating severity yang diperoleh dari rating standart six sigma yang telah disesuaikan dengan kondisi perusahaan. Pendefinisian untuk setiap ratting severity dapat dilihat pada halaman 28. 
2. Occurance

Uraian kriteria dari rating severity yang diperoleh dari rating standart six sigma yang telah disesuaikan dengan kondisi perusahaan. Pendefinisian untuk setiap ratting occurance dapat dilihat pada halaman 29.

3. Detection.

Uraian kriteria dari rating severity yang diperoleh dari rating standart six sigma yang telah disesuaikan dengan kondisi perusahaan. Pendefinisian untuk setiap ratting detection dapat dilihat pada halaman 30.

Nilai ranking yang muncul dalam Severity, Occurance dan Detection pada tabel FMEA berikut adalah hasil rata-rata dari pembobotan yang telah dilakukan oleh 2 responden diatas yang didapatkan dari hasil penyebaran kuisioner.

4.6 Risk Priority Number (RPN)

Risk Priority Number (RPN) merupakan hasil perkalian dari Severity, Occurance dan Detection. Berdasarkan nilai kritis RPN dan atas persetujuan perusahaan maka diperoleh 3 kerusakan kritis. Dengan nilai RPN dari keempat kerusakan tersebut berada di atas 135 yang merupakan nilai paling kritis RPN.

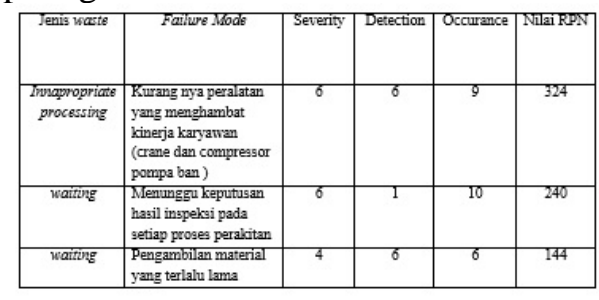

4.6 Rekomendasi usulan perbaikan dari hasil FMEA

Proses perakitan trailer 40 feet terdiri dari beberapa aktifitas yaitu rakit rangka body, rakit lantai, pengecatan lantai dan rangka, pemasangan spare part dan acessoris trailer. Pada proses perakitan trailer tersebut muncul waste yang dominan dari 7 waste yang ada yaitu waiting inventory motion dan innappriate processing. Berdasarkan analisis hasil FMEA yang sudah dilakukan pada tahap sebelumnya maka dapat diusulkan rekomendasi perbaikan

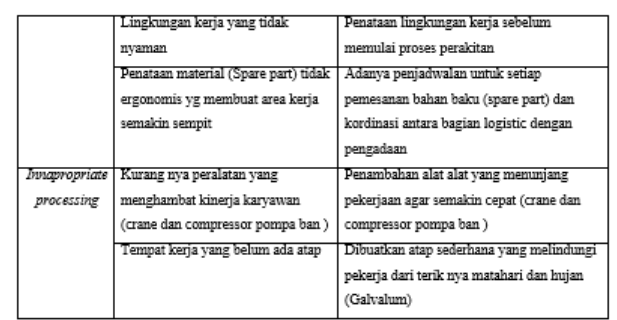

5. Analisa Dan Pembahasan

5.1 Analisa awal proses perakitan trailer dengan Value Stream Mapping

Menurut metode VSM aliran

fisik dan aliran informasi yang telah dibuat, dapat di identifikasi

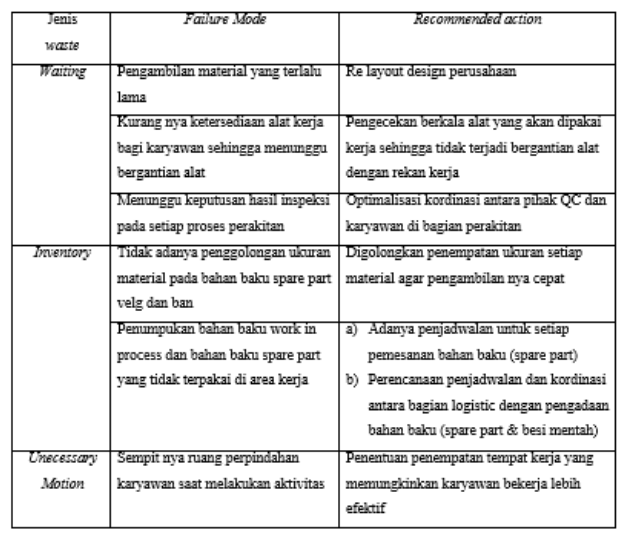

permasalahan yang terjadi dalam proses perakitan trailer 40 feet pada PT.

Sumber Urip Sejati permasalahan tersebut antara lain :

Dimulai karna adanya penumpukan inventory pada area perakitan berupa tabung angin, spare part velg dan ban sehingga menghambat gerakan yang mempengaruhi kinerja kerja karyawan (unnecessary motion). Pemborosan sebenarnya terjadi karena banyaknya material yang menumpuk di sisi area kerja dikarenakan gudang spare part selalu penuh dan sisa dari gudang spare part di tumpuk di area sebelah gudang

Kemudian ada proses yang tidak bernilai tambah dan harus dijalani seperti proses pengambilan bahan baku berupa besi mentah wf, pengambilan material (spare part), pembersihan sisa sisa plat hasil potongan dalam proses perakitan rangka body dan lantai proses terserbut akan mengakibatkan para pekerja menunggu 
(waiting) sehingga waktu yg menunggu akan dibuat istirahat bagi para pekerja (small stop)

Kurang lengkapnya peralatan peralatan penunjang bagi para pekerja (compressor, crane, mesin bubut, dll) yang mengakibatkan para pekerja akan menggunakan alat manual dan membutuhkan waktu extra ketika menggunakan nya (inappropriate processing). serta di dalam ruang lingkup perakitan, belum adanya atap yang mengakibatkan pekerja akan kepanasan (dehidrasi) dan kalau hujan pekerja akan berhenti sejenak.

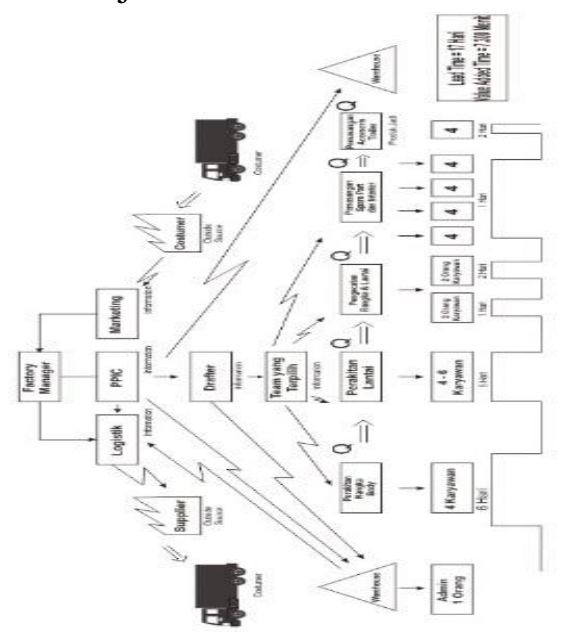

Future State Mapping

5.2 Analisis future state mapping value added activity dan non added value activity

1. value added activity

Jenis pemborosan pada value added activity dari value stream mapping direkap dengan bentuk tabel agar mudah untuk analisis. Jenis pemborosan pada value added activity

\begin{tabular}{|c|c|c|c|}
\hline No & Aktivitas & $\begin{array}{l}\text { Rata rata } \\
\text { walthy VA }\end{array}$ & $\begin{array}{c}\text { Jenis } \\
\text { Pemborosan } \\
\text { (waste) }\end{array}$ \\
\hline 1 & $\begin{array}{l}\text { Proses peralitan Rangkas Body } \\
\text { - Proses potong bahan balky } \\
\text { - Mengubur kepresisian rangka } \\
\text { - Memotong bagian plat yang tidak } \\
\text { perly }\end{array}$ & 5 bari & $\begin{array}{l}\text { Motion } \\
\text { Waiting } \\
\text { Broccers }\end{array}$ \\
\hline 2 & $\begin{array}{l}\text { Proses pengelasan (Stel) } \\
\text { - Proses pewvambungan plat }\end{array}$ & 1 Hari & Waiting \\
\hline 3 & $\begin{array}{l}\text { Inagelasi } \\
\text { - Inspeksi kepresisian rangka } \\
\text { - Inspeksi titik point las } \\
\text { - Inspekgi sambungan }\end{array}$ & $2 \mathrm{Jam}$ & $\begin{array}{l}\text { Motion } \\
\text { Waiting } \\
\text { Waiting }\end{array}$ \\
\hline
\end{tabular}

\begin{tabular}{|c|c|c|c|}
\hline 4 & \begin{tabular}{|l} 
Proses perakitan lantai \\
- Proses penvusuvuan lastai \\
- Proses pemotongan \\
- Proses penguburan kepresisian
\end{tabular} & 5 hard & $\begin{array}{l}\text { Motion } \\
\text { Waiting } \\
\text { Waiting }\end{array}$ \\
\hline 5 & $\begin{array}{l}\text { Proses Las fall } \\
\text { - Proses pensambungan lantai ke } \\
\text { canglka body }\end{array}$ & $2 \mathrm{Hari}$ & Waiting \\
\hline 6 & 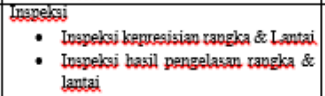 & $2 \mathrm{Jam}$ & $\begin{array}{l}\text { Waiting } \\
\text { Waiting }\end{array}$ \\
\hline 7 & 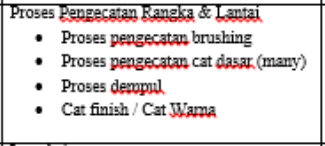 & $4 \mathrm{Bari}$ & $\begin{array}{l}\text { Waiting } \\
\text { Waiting } \\
\text { Procces } \\
\text { Waiting }\end{array}$ \\
\hline 8 & 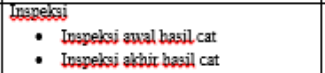 & $2 \mathrm{Jam}$ & $\begin{array}{l}\text { Waiting } \\
\text { Waiting }\end{array}$ \\
\hline 9 & 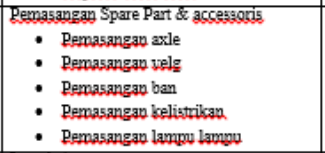 & $2 \mathrm{Barli}$ & $\begin{array}{l}\text { Motion } \\
\text { Proccer } \\
\text { Broccer } \\
\text { Brocces } \\
\text { Waiting }\end{array}$ \\
\hline 10 & $\begin{array}{l}\text { Trapelegi } \\
\text { - Check Up } \\
\text { - Tune Up } \\
\text { - Inepeksi fungsi Lampu }\end{array}$ & $2 \mathrm{Jam}$ & $\begin{array}{l}\text { Waiting } \\
\text { Waiting } \\
\text { Waiting }\end{array}$ \\
\hline
\end{tabular}

\section{Non-value added activity}

Jenis pemborosan pada Non value added activity dari value stream mapping direkap dengan bentuk tabel agar mudah untuk dianalisis. Jenis pemborosan pada non value added ativity

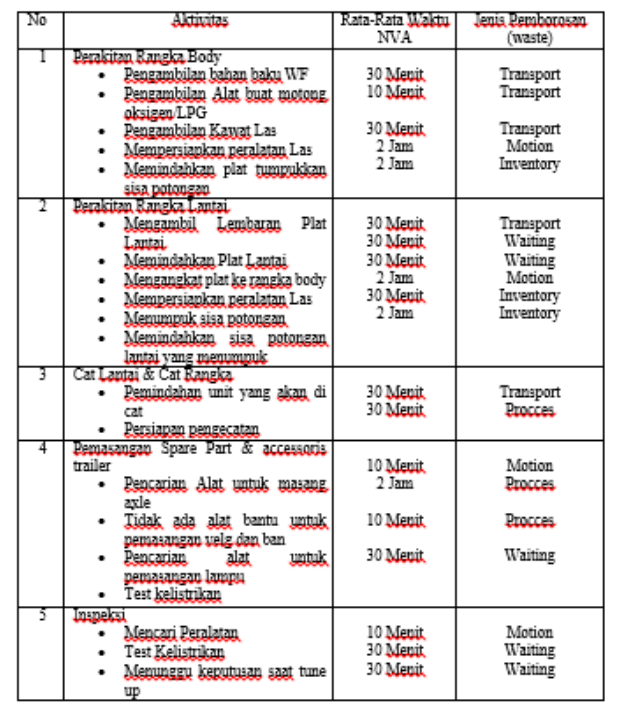

5.3 Analisis Process Activity Mapping (Future State)

Berdasarkan hasil pengolahan data dalam tahap sebelumnya maka dapat digambarkan future process activity mapping. Dalam penggunaanya alat ini sering digunakan oleh beberapa ahli teknik industry untuk memetakan seluruh aktivitas secara detail untuk mengeliminasi waste, ketidak konsistenan, dan keirasionalan di area kerja sehingga dapat meningkatkan efisiensi kinerja melalui peningkatan 
kualitas, mempercepat proses serta mereduksi biaya.

Process activity mapping memberikan sebuah deskripsi tentang aliran fisik dan informasi, waktu yang diperlukan untuk setiap aktivitas jarak yang ditempuh dan pengukuran inventory dalam setiap tahap produksi. Kemudahan dalam mengidentifikasi sebuah aktivitas dibagi menjadi lima golongan yaitu operasi, transportasi, inventory, inspeksi dan delay. Operasi adalah aktivitas yang bernilai tambah (VA). Sedangkan inspeksi dan transportasi berjenis penting tapi tidak bernilai tambah (NNVA). Kemudian delay adalah aktivitas yang tidak bernilai tambah (NVA) yang sebaiknya dihindari untuk meningkatkan efisiensi.

5.4 Analisa perbandingan future state proses activity mapping dengan current state proses activity mapping

\begin{tabular}{|c|c|c|c|}
\hline Alctivitas & Jenis Alstivitas & $\begin{array}{l}\text { Cworent staxe } \\
\text { mapping } \\
\text { (Waltalu) }\end{array}$ & $\begin{array}{c}\text { Futwre stare } \\
\text { mapping } \\
\text { (Waktu) }\end{array}$ \\
\hline $\begin{array}{l}\text { Pengambilan } \\
\text { bahan balkn WF }\end{array}$ & NNVA & 30 DLenit & 15 Menit \\
\hline $\begin{array}{l}\text { Rengambilang alat } \\
\text { buat motong } \\
\text { (akoigen LPG) }\end{array}$ & NNVA & 10 denit & 5Dlenit \\
\hline $\begin{array}{l}\text { Rengambilan } \\
\text { bavivat las }\end{array}$ & NNVA & 30 Drenit & 10 Slenit \\
\hline $\begin{array}{l}\text { Mempergiapkan } \\
\text { peralatan las }\end{array}$ & NVA & $2 \mathrm{Jam}$ & 30 Stenit \\
\hline $\begin{array}{l}\text { Demindahkan plat } \\
\text { gisa }\end{array}$ & NVA & $2 \mathrm{Jam}$ & 30 denit \\
\hline Jasperag Lantai & NNVA & $5 \mathrm{Jam}$ & $2 \mathrm{Jam}$ \\
\hline $\begin{array}{l}\text { Proses pengecatan } \\
\text { Brushing }\end{array}$ & VA & 1 Hari & 3/2 Hari \\
\hline $\begin{array}{l}\text { Proses pengecatan } \\
\text { cat dagar (cat } \\
\text { many) }\end{array}$ & $\mathrm{VA}$ & 1 Hard & T/2 Bari \\
\hline Cat finish & $\mathrm{VA}$ & $2 \mathrm{Hanh}$ & $1 \mathrm{Harn}$ \\
\hline $\begin{array}{l}\text { Inapelesi cat lantai } \\
\& \text { b body }\end{array}$ & NNVA & $2 \mathrm{Jam}$ & 30 DLenit \\
\hline Pemsasangan ban & $\mathrm{VA}$ & $2 \operatorname{Jam}$ & 30 Menit \\
\hline $\begin{array}{l}\text { Remindahan ekor } \\
\text { ke keppala }\end{array}$ & $\mathrm{VA}$ & $2 \mathrm{Jam}$ & $1 \mathrm{Jam}$ \\
\hline $\begin{array}{l}\text { Penyanobungam } \\
\text { ekor ke kepala } \\
\text { trailer }\end{array}$ & $\mathrm{VA}$ & $2 \mathrm{Jam}$ & 10 Dlenit \\
\hline
\end{tabular}

5.5 Analisis perbandingan value stream mapping (VSM) current state dengan future state pada proses perakitan trailer 40 feet

VSM perbaikan ini digunakan untuk menggambarkan aliran nilai sistem perakitan trailer 40 feet setelah dilakukan perbaikan. Berdasarkan gambar 5.2 future state mapping, dapat diketahui bahwa perusahaan mampu mengurangi lead time proses perakitan trailer 40 feet sebesar 1.850 menit sehingga perusahaan mampu menyelesaikan perakitan trailer 40 feet selama 18 hari yang sebelumnya 22 hari

\section{Kesimpulan Dan Saran}

Berdasarkan pengolahan data dan analisa dalam penelitian ini, maka didapatkan kesimpulan yaitu :

1. Berdasarkan hasil penelitian, didapatkan jenis pemborosan yang paling sering terjadi adalah waiting, Motion, Innappropriate processing, Inventory, Transportation, Defect, over production.

2. Dari hasil identifikasi berdasarkan perhitungan rata-rata urutan keseringan waste yang terjadi pada proses perakitan trailer 40 feet adalah waiting $(20,3 \%)$, Motion (20,2\%), Innappropriate processing $(18,8 \%)$, Inventory $(18,1 \%)$,

- Waste waiting terjadi karena sering nya menunggu material datang, dan menunggu proses inspeksi selesai.

- Waste motion terjadi karena kondisi ruang kerja perusahaan yang sempit dan belum adanya atap

- Waste Inappropriate processing terjadi karena proses yang tidak efisien dan efektif

- Waste Inventory terjadi karena banyak nya plat plat sisa yang tidak terpakai serta banyaknya material bahan baku disekitar area kerja.

- Mapping tools yang akan digunakan berdasarkan hasil konveksi skor kuisioner kedalam matrik VALSAT adalah proses activity mapping (39,3\%).

- Value Added Ratio (VAR) sebelum perbaikan mempunyai prosentase nilai sebesar $88,52 \%$ sedangkan penerapan perbaikan nilai VAR menjadi $92,29 \%$

- Dari penggunaan mapping tools, process activity mapping dapat diketahui bahwa prosentase aktivitas inspection adalah $(6,76 \%)$ memiliki proporsi waktu terbesar kedua, dimana aktifitas ini termasuk dalam aktifitas necessary non value added. Setelah dilakukan perbaikan aktifitas inspection maka hasil dari nilai prosentasenya adalah $(4,94 \%)$.

3. Berdasarkan analisis FMEA maka didapatkan Faktor faktor yang menjadi penyebab terjadi nya waste yaitu

- kurang nya peralatan yang menghambat kinerja karyawan contoh crane dan compressor pompa ban

- menunggu keputusan hasil inspeksi pada setiap proses perakitan 
- menunggu pengambilan material yang terlalu lama

4. Hasil dari analisa value stream mapping current state perusahaan sebelumnya dapat merakit trailer 40 feet selama 22 Hari terlambat 2 hari dari due date konsumen. Setelah ada usulan perbaikan (future state) perusahaan dapat merakit trailer 40 feet selama 18 hari lebih cepat 2 hari dari due date konsumen.

\section{DAFTAR PUSTAKA}

Akbar, Faisal. (2011). Perancangan Lean manufacturing System dengan Pendekatan Cost Integrated Value Stream Mapping Studi Kasus Pada Industri Otomotif. Depok. Universitas Indonesia.

Anvari A, I. Y., Hojjati S M H (2011). A Study On Total Quality Management And Lean Manufacturing: Through Lean Thinking Approach. World Applied Sciences Journal, Vol. 12, No. 9, pp. 11-19.

Bicheno, J., 1991. 34 for Quality, PICSIE Books, Buckingham.

Carreira, B (2005). Lean Manufacturing That Works. New York: AMACOM.

Carroll, B. (2001). Leadership in lean, empowering manufacturing organizations. Journal of Organizational Excellence, 20, 81-90.

Fanani, Zaenal. 2011. Implementasi Lean Manufacturing Untuk Peningkatan Produktivitas (Studi Kasus Pada Pt. Ekamas Fortuna Malang), Tesis Program Magister Manajemen Teknologi, ITS Surabaya.

Gaspersz, Vincent. (2006). "Continous Cost Reduction Through Lean Sigma

Approach". Jakarta. PT. Gramedia Pustaka Utama.

Gaspersz, Vincent. (2007), Lean Six Sigma for Manufacturing and Service Industries. Jakarta : PT Gramedia Pustaka Utama.

Hines, Peter, and Taylor, David. (2000), “Going Lean". Proceeding of Lean Enterprise Research Centre Cardiff Business School, UK.

Hines, Peter and Rich, Nick (2001). The Seven Value Stream Mapping Tools.
Manufacturing Operation and Supply Chain Management: Lean Approach, David Taylor and David Brunt. (editor). Thomas Learning. London.

Hines \& Rich, (1997), Value Stream Analysis Tools (VALSAT).

Wignjosoebroto, Sritomo. 2008. Ergonomi Studi Gerak dan Waktu. Surabaya:Guna Widya.

Hirano, Hiroyuki (2009), The Just In Time Production System 2nd edition volume 2,New York, A Productivity Press Book.

Howell, J.M., and Hall-Merenda, K.E. 1999. The Ties That Bind: The Impact of Leader-Member Exchange, Transformational and Transactional Leadership, and Distance on Predicting Follower Performance. Journal of Applied Psychology, 84 (5): 395-401.

Lane, Greg, (2000), Made to Order Lean,Spain.

Liker, J.K. dan Meier, D. (2007). The Toyota Way Fieldbook. Jakarta : Erlangga Group.

Kusuma, Sabta Adi. (2010). Penerapan Lean Manufacturing Dalam Mengidentifikasi Dan Meminimasi Waste Di PT. Hilton Surabaya. Undergraduate Thesis. Surabaya: UPN Jatim. 